district there were fairly numerous sporadic cases of the disease, in some of which I found the parasites of kalaazar, thus establishing the identity of this small outbreak with the more extensive ones already described.

I have now completed my survey of the subject from the epidemiological point of view, having.treated it in considerable detail, because I think the vast economic importance of these terrible spreading fevers is not yet fully realized out of India, and that the necessity of olearly distinguishing between the epidemic and the :sporadic forms of the disease cannot be too strongly insisted on. The two disastrous outbreaks I have described both occurred within the last half century, their spread being conceivably assisted by improved communications in the affected tracts; and, as it is impossible to say when a fresh epidemic may be started, we must be on our guard against them, for in no disease is it so true that knowledge is power, as I shall hope to show you in the course of my remaining lectures.

\section{A CASE OF CEREBRO-SPINAL MENINGITIS,}

WITE OBSERVATIONS ON A PLEOMORPHIC DIPLOCOCCUS OBTAINED BY LUMBAR PUNCTURE.

BY

J. SINGLETON DARLING, M.B.DuB., ETC., LURGAN ;

$$
\text { AND }
$$

W. JAMES WILSON, B.A., M.B., D.P.H.CAMB. MIDDELL DEMONSTRATOR IN PATHOLOGY AND BACTERIOLOGX, QUEEN'S COLLEGE ; PATHOLOGIST TO THE MATER INFIRMORUM HOSPITAL, BELFAST.

THE micrococcus described in this paper was obtained in pure culture from three different samples of cerebro-spinal Aluid taken by lumbar puncture from a case of sporadic cerebro-spinal meningitis. The coccus assumed bacillary form on Conradi-Drigalski medium; was Gram-positive grew well on ordinary media; did not liquefy gelatine; clotted milk; produced no indol ; produced no gas in sugarcontaining media; was pathogenic for rabbits.

The patient-J. C., male, aged 40, married-was first seen by one of us(J. S. D.) on August 11th, 1906.

History.-His health had always been good. Hehad been a hard drinker up to eighteen months earlier but since then had been a total abstainer. Five weeks before his present illness he had been away from work for two weeks suffering from muscular pains, headache, and shivering fits. He went back to work for three weeks, but on August 11th there was a returi of the pains in the limbs, headache, and anorexia, and towards night he becamedelirious.

Condition on Admission to Hospital.-August 13th. Temperature $101.7^{\circ} \mathrm{F}$., pulse 102 , delirious, neck retracted, pupils perature 101.70 ., pular ; he vomited for the one and only time; there was retention of urine. He slept fitfully after the administration of bromides and chloral.

August 14th. No change; bowels moved, calomel having been given for the second time. The catheter was still required ; urine contained no albumen. There was no sign at this or any other time of heart trouble.

August 15th to 21st. Some improvement ; took milk in quantity ; passed urine naturally ; complained greatly of stiffness and pain in the back and limbs; marked headache; but never any pain in the joints. Towards night became very restless,

August 21st. Kernig's sign well marked.

August 24th. Six drachms of clear fluid were removed from the spinal canal, the needle being introduced immediately below the fourth lumbar vertebra (with thorough aseptic precsutions); this seemed to give relief.

August 29th. Lumbar puncture was again performed, 5 drachms being withdrawn, and considerable relief was afforded.

August 30th. The patient was-much worse; refused all nourishment; and had incontinence of faeces; temperature subnormal ; pulse 130 .

September 2nd. Nine drachms of clear fluid withdrawn from the spinal canal, the puncture being practised below the second lumbar vertebra, as no fluid came on puncturing below the fourth lumbar.

September 3rd. The patient was moribund. A small quantity of blood was taken for purposes of agglutination. He died at 8.45 p.m.

\section{Bacteriological Examination of the Cerebro-} SPINAL FLUID.

As stated above, the spinal cavity was punctured on three occasions, 'and the fluid so obtained was immediately put into sterilized bottles and forwarded to the laboratory for examination. The three samples were identical in all respects, and each sample was found to contain in pure culture the organism about to be described. The fluid was limpid; on centrifugalizing, there was a slight deposit consisting of polpmorphonuclear leucocytes and a number of cocci; the latter were invariably extracellular, Gram-positive, measured $0.8 \mu$ in diameter, were spherical diplococci in most instances, but occasionally there was slight flattening of the apposed surfaces. . For the purposes of this paper the coccus will be spoken of as the "meningeal diplococcus." This organism grew well on the usual laboratory media - peptone water excepted-and furnished an abundant growth after eighteen hours. The cultures showed considerable vitality, being alive after two months at room temperature.

\section{Cultural Characteristics.}

Gelatin Stab. -Along the stab there is a dagger-like line of growth having a finely-notched edge. There is no surface growth and no liquefaction of the medium.

Gelatin Plates - The surface colonies are similar to those on agar, but are smaller. The deep colonies are perfectly circular, and are of a uniform yellowish-brown colour. The edge of the colonies is smooth.

Agar.-In stroke cultures there is a spreading grey film of growth with a finely-indented margin. The growth, which appears bluish by transmitted light, and which somewhat closely resembles that of the Bacillus typhosus, presents a uniform appearance, having very little tendency to form isolated colonies.

Agar Plates. - At the end of forty-eight hours the surface colonies, which are circular in outline measure $0.5 \mathrm{~mm}$. in diameter. The centre of the colony is yellowish, the periphery is translucent, the edge is crenated. The deep colonies, which is translucent, the edge is crenated. The deep colonies, which are much smaller, are of a uniform

and have the shape of a whetstone.
Alkali-Albumen Jelly (Lorrain Smith).-Greyish spreading growth.

Potato.-Greyish, raised moist growth.

Conradi-Drigalski Medium.-Stroke cultures present an appearance identical with that of $B$. coli communis-that is, greyish lines of vigorous growth on a bright red background. Bouillon.-Copious growth both aërobically and anaërobically. No indol was formed in sugar-free bouillon. Peptone Water.-Practically no growth.

Milk.-In twenty-four hours, acidity; in forty-eight hours, clotting.

The effect of the micrococcus on certain sugars and alcohols is shown in the following table. No gas was evolved in any case.

TABLE I.

\begin{tabular}{|c|c|c|c|c|c|c|c|c|}
\hline & 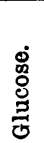 & 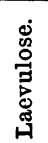 & 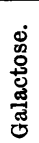 & 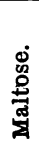 & $\begin{array}{l}0 \\
0 \\
0 \\
0 \\
0\end{array}$ & 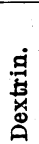 & $\begin{array}{l}\text { 苞 } \\
\text { 节 }\end{array}$ & 官 \\
\hline Meningeal diplococcus.. & + & + & + & + & - & + & - & + \\
\hline
\end{tabular}

$$
\text { The + signifies formation of acid. }
$$

Further study of the meningeal diplococcus demonstrated its relationship to the Streptococcus faecalis group. In this connexion I have followed Gordon in his attempt to differentiate the streptococci by using the nine tests shown on the accompanying table. The + signifies acid production; no gas formed in any instance. I have included for comparison the changes produced by the type form of the Streptococcus faecalis group as given by Andrewes and Horder. ${ }^{2}$

TabLe II.

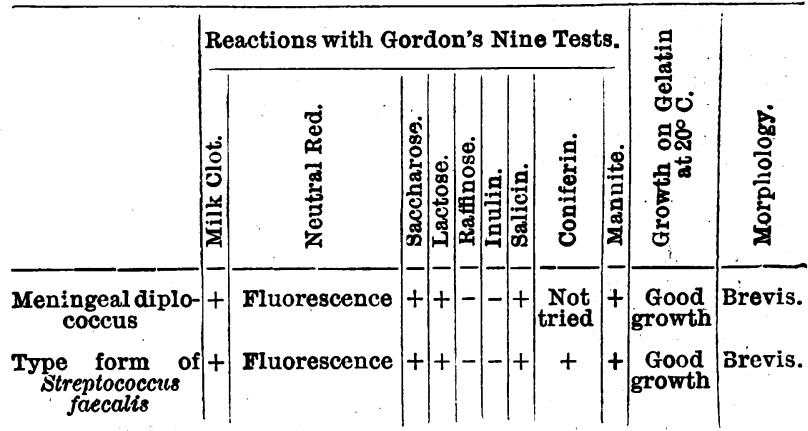

It will be seen that the changes produced by the two organisms are identical, so that this meningeal diplococcus evidently belongs to the Streptoccus faecalis group. It is interesting in this connexion to note that Andrewes and Horder ${ }^{2}$ have shown that an organism sent by Beattie as 
a typical Diplococcus rheumaticus also belongs to this group.

The presence of the meningeal diplococcus in the cerebro-spinal fluid was not due to a mere terminal infection, as it was isolated shortly after the onset of the illness, many days before the fatal issue.

\section{MORPHOLOGY}

On agar, gelatin, blood serum, potato, the organism appears as a very minute micrococcus, $0.6 \mu$ to $1.0 \mu$ in diameter, for the most part presenting a grouping similar to that of a streptococcus, but a few occur in pairs, and singly and in short chains.

In bouillon the organism appears as a diplococcus, having the oval shape of Fraenkel's pneumococcus, and measuring $1.2 \mu$ in its longest diameter. Bat the interesting point connected with this organism is the fact that after a few hours on the Conradi-Drigalski medium it assumes a bacillary or spindle conradi-Drigalski medium it assumes a bacillary or spindle shape. The individual microbes are much larger than on other
media. The large swollen spindles average $1.7 \mu$ in their media. The large swollen spindles average $1.7 \mu$ in their $3.4 \mu$ by $1.2 \mu$, and some as much as $5 \mu$ by $1.7 \mu$ (see photomicrograph)

On transplanting back from the Drigalski medium on to agar or blood serum the organism reverts to the micrococous agar or blo form. Tho puris of the agar and from the Drigalski plates when the same changes

On mixing a loopful of growth from the Drigalski medium with water a uniform emulsion, as in the case of the growth on agar, is not obtained, but clumps appear very similar to those in a positive agolutingtive rosine agglutinative reaction. Staining with dilute carbolfuchsin shows the pre sence of a mucilaginous substance in which the cocci lie embedded, and which gives them the appearance of being surrounded by a capsule.

The Assumption of

THE Bacillary Form BY Coccr.

Arloing and Chantre ${ }^{3}$ observed a streptococcus, under conditions the nature of which they could not determine, assume a bacillary form. Durham ${ }^{4}$ has shown that a bacillary form occurs in cultures of the Micrococcus melitensis wh i ch have been started for a few days at body temperature, and then kept for a few weeks (for example, four) at room temperature. Muir and Ritchie ${ }^{5}$ have also noticed this phenomenon in young cultures of the Micrococcus melitensis. Gordon ${ }^{6}$ demonstrated that a streptococcus occurring in the throat in cases of scarlet fever, and called by him "Streptococcus scarlatinae" had a tendency, especially on solid media, to assume a bacillary form. W. V. Shaw" observed that Wassermann's "Streptococcus aus chorea," after forty-eight hours at $37^{\circ} \mathrm{C}$., assumed a bacillary form.

Through the kindness of Dr. Andrewes in forwarding me specimens, I was able to test the effect of growth on the Conradi-Drigalski medium on different types of streptococci, including a specimen of the Diplococcus rheumaticus obtained by Beattie from Paine. It was found that a typical Streptococcus faecalis and the Diplococcus rheumaticus grew vigorously on the Drigalsk medium, and that the bacillary form was very marked in fact, numerous short flaments were observed. A Streptococcus faecalis which differed from the type form in that it did not clot milk, grew vigorously on the Conradi-Drigalski medium, but had little tendency to assume a bacillary form. A variant of the salivariu type failed to grow on the Conradi-Drigalski medium, though by subcultures on other media it was proved to be living. A typical streptococcus pyogenes grew fairly well on the Conradi-Drigalski medium, but did not depart from the coccus form. These results add further proof that the "meningeal diplococcus" and the Diplococcus rheumaticus are members of the Streptococcus faecalis group. I then tried to find out what constituent of the Conradi-Drigalski medium brought about the pleomorphism.

On a medium identical with the Drigalski medium, but containing no crystal violet, all the different groups, including the salivarius type, grew vigorously and produced much acid. The different types had much the same morphology as on the Drigalski medium, but the assumption of the bacillary form was not so marked, so that the crystal violet contributes something to the conditions inducing the plemorphism. The salivarius type grew actively on this medium, and assumed a bacillary form. On nutrose agar all the types appeared as minute cocci. On lactose agar the Streptococcus pyogenes maintained its circular form, whilst all the others were oval.

It would appear, then, that the crystal violet and the lactose are the active constituents in inducing the change of form, but probably all the different elements in the medium contribute to the result, and it may be that the acid produced in the medium is not without its effect. These observations may be of some use in the classification and recognition of the different types of streptococci.

Pathogenesis.

The results of the second of the two following experiments are very similar to some of those obtained by Beattie with the "Diplococcus rheumaticus."

First Experiment.-A mouse, inoculated subcutaneously with an agar culture, remained lively up to a few dsys before eighteen days after the inoculation. The meningeal diplococcus was not recovered from its tissues, and there was no evidence to show that it caused the death of the animal.

Second Experiment. On January 21st (six months since isolation of coccus) a rabbit was inoculated intravenously with the contents of four agar the contents of four agar the original cultivation. January 24th. - Rabbit lame in right fore limb, which it holds op when hopping about. No suppuration at point of inoculation." No. evidence of endocarditis on auscultation. Rabbit quite lively. and takes food freely.

January 30th.-Condition of the rabbit the same as on January 24 th. On this day the rabbit was killed. There was January $24 \mathrm{th}$. On this day the rabbit was killed. There was found slight swelling of the elbow-joint of the right fore limb,
and a wedge-shaped pale infarct of the right kidney ; in other and a wedge-shaped pale infarct of the right kidney; in other
respects the animal's body appeared to be normal. The meningeal diplococcus was recovered in pure culture from the urine, brain, spinal cord. and right elbow-joint. It was not recovered from the heart's blood or the right wrist-joint. In the right elbow-joint there was a small amount of turbid fluid. There was no evidence of suppuration in any part of the body

Andrewes and Horder ${ }^{2}$ observed that many of the cocci in cases of malignant endocarditis were of the Streptococcus faecalis and Streptococcus salivarius classes, and were very slightly pathogenic to animals. Why these feebly pathogenic organisms should cause a fatal disease in man is strange. Andrewes and Horder say : "It may be that the very lowness of the virulence of these habitual saprophytes of the alimentary canal accounts for the lack of efficient resistance on the part of the patient, there being. no adequate stimulus to call forth the defensive mechanisms necessary for the destruction of the cocci."

\section{Agglutination.}

The patient's blood serum in dilutions of 1 in 14 and 1 in 50 yielded negative results. The effect of inoculation is to increase the agglutinins in the blood of the 


\begin{tabular}{|c|c|c|c|c|c|c|c|c|c|c|c|}
\hline \multicolumn{4}{|c|}{ Blood Serum. } & 1 in 14. & 1 in 40. & 1 in 80. & 1 in 160. & 1 in 320. & 1 in 640. & 1 in 1,280 . & 1 in 2,560 . \\
\hline Control rabbit ... & $\cdots$ & $\cdots$ & .. & $\begin{array}{l}\text { Clumps in } \\
15 \text { mins. }\end{array}$ & $\begin{array}{l}\text { Clumps } \\
30 \text { mins. }\end{array}$ & $\begin{array}{l}\text { No clumps } \\
1 \text { hour }\end{array}$ & No clumps & - & - & - & - \\
\hline Inoculated rabbit & $\cdots$ & $\cdots$ & $\cdots$ & $\begin{array}{l}\text { Clumps } \\
\text { at once. }\end{array}$ & $\begin{array}{l}\text { Clumps } \\
10 \text { mins. }\end{array}$ & $\begin{array}{l}\text { Clumps } \\
10 \text { mins. }\end{array}$ & $\begin{array}{l}\text { Clumps } \\
10 \text { mins. }\end{array}$ & $\begin{array}{l}\text { Clumps } \\
10 \text { mins. }\end{array}$ & $\begin{array}{l}\text { Clumps } \\
15 \text { mins. }\end{array}$ & $\begin{array}{l}\text { Clumps } \\
50 \text { mins. }\end{array}$ & $\begin{array}{l}\text { None } \\
1 \text { hour. }\end{array}$ \\
\hline
\end{tabular}

Opsonin.-The blood of inoculated rabbit compared with that of a control rabbit had an opsonic index of 1.2 .

rabbit, as shown in Table III. An emulsion of an 18 hours' agar culture in 0.75 saline was used in performing the test.

Concu usion.

The "meningeal diplococcus" belongs to the Streptococcus faecalis group, and is identical with the "Micrococcus rherumaticus."

We wish to thank Mr. Andrew and Dr. Kirkhope, to whose kindness and skill we are indebted for the photo- micrograph, and Professor Symmers for 'performing the inoculations.

Horder, Lancet, 8eptember 15th, 11 th, $1905, p .1400 .2$ Andrewes and Chantre, vide Rodet, De la variabilite dans les microbes, p. 21 Bailliere, Paris, 1894.' \& Durham, Journ. Path. and Bacteriol., v, p. 377. 5 Muir and Ritchie, Manual of Bacteriology, 3rd edition, p. 434 6 Gordon, Report of the Medical Officer to the Local Government Board for 1900-1, p. 353. ${ }^{7}$ W. V. Shaw, Journ. Path. and Baction., vol. ix, p. 275 .
p. 160 . 8 Beattie, Journ. Path. and Bacteriol.,

\section{ME M O R A N D I MEDICAL, SURGICAL, OBSTETRICAL.}

RUPTURE OF DILATED AORTA: LEAKAGE BRUIT. THe following case may be of interest on account of the rarity with which a leakage bruit is ever experienced in rapidly-fatal internal haemorrhage.

A few days ago I was called urgently to an old man-a pauper patient, aged 71, who had suddenly become collapsed while sitting on the water-closet. Before my arrival he had been lifted on to a bed near at hand. I found the man pale, collapsed, and quite unconscious pupils moderately wide, lips blue. The pulse was not perceptible at the wrists, and he was only taking short breaths at intervals. On auscultation over the precordial region the cardiac sounds could be heard feebly, but dis tinct from a continuous adventitious sound which may be described as "gurgling" or "lapping," as of a cat lapping milk. The bruit, which altered in character, the succes. sive laps becoming more rapid and finally lost, was quite different from any sounds I have ever heard in the chest, and suggested at once the leakage of blood. I thought the man had ruptured his heart muscle. He rapidly succumbed.

At the post-mortem examination the pericardium was greatly distended with dark fluid and clotted blood. The heart was hypertrophied but no rent in it could be found. In the external wall of the aorta were seen large darkbluish areas almost encircling the vessel. They looked like gangrenous patches but were really blood-clot infiltrations. The first part of the aorta was somewhat dilated and very atheromatous in parts, and in the inner coats of the wall near to the pulmonary artery was an irregular longitudinal valvular slit quite $1 \frac{1}{2}$ in. in length, through which the blood had leaked. From this it had travelled in the coats of the vessel, and escaped into the pericardium posteriorly. The valves of the heart were in good condition. The rectum was found loaded.

The man had not had any symptoms, his only trouble being a chronic bronchitis. A point to remark about the bruit heard was its total independence of the cardiac sounds. Presumably in rupture of the ventricle the sound of leakage if ever heard would be intimately related to the cardiac systole.

London, S.E.

F. B. SkerReTt, M.B., B.Sc., D.P.H.

ACUTE INTUSSUSCEPTION.

ON October 10th, 1906, I hud a telephone message to see a patient, W. A. P., aged 3 years.

The history was as follows: When going upstairs carry ing some toys he slipped and fell down four steps. He did not cry at the time, but continued his way up to the bedroom; as soon as he arrived there he began to cry, complaining of severe pain in the region of the umbilicus this pain soon disappeared, but returned in about five minutes.

I saw him half an hour after the accident, when his general condition was rather alarming. The forehead was covered with cold sweats, the face pinched, the pulse 130 and irregular, and the temperature normal. Pains were coming on frequently, but there was no vomiting. The abdomen was not distended, but there was a distinct swelling in the right iliac fossa, and extending rather higher up than the usual ileo-caecal variety, and this was more pronounced during the attacks of pain. Vomiting commenced in about an hour after the accident happened.

The patient was at once placed under the influence of morphine, and three hours after the accident an injection of sterilized warm water was given by means of a catheter connected with an indiarubber tubing and funnel. After injecting about a pint into the bowel, I placed my right hand over the swelling, while with my left hand I grasped the abdominal wall and small intestines and pulled gently downwards and towards the left side; suddenly, to my satisfaction, the swelling disappeared from under my right hand.

He was kept in bed for four days, and had only small quantities of liquid nourishment. Then I ordered some eastor oil, the bowels acted normally, and the little patient has been perfectly well ever since.

In acute intussusception it is of the utmost importance that the case should be seen and diagnosed early, and at once put under the influence of morphine. An attempt at reduction should also be made as soon as possible, as in this way a good many lives can be saved. In this particular case an injection only was not sufficient, but a little traction applied worked admirably.

$\begin{array}{ll}\text { Cardiff. } & \text { W. G. WILliams, M.B., Ch.B. }\end{array}$

\section{RUPTURE OF GASTRIC ULCER INTO THE} POSTERIOR MEDIASTINUM.

J. K., male, aged 52 years, has suffered from gastric dilatation for about six years, during which many forms of treatment have been adopted with more or less success. About eighteen months ago symptoms of ulceration showed themselves, but with suitable treatment these abated, only to recur from time to time. Last November he was sent to Manchester Infirmary, with a view to having gastro-enterostomy performed, but his condition was so good while there that it was not considered necessary.

He returned home, and after about a fortnight began with the old symptoms, and was admitted to the Cottage Hospital at Penrith on January 10th, 1907. : He was emaciated and complaining of pain in the epigastrium ; the stomach was only moderately distended; he vomited at intervale a large amount of brown-coloured fluid; his bowels were constipated; there was also a considerable degree of anaemia. He was put on a liquid and predigested diet, and the stomach washed out for a few days, when pain and vomiting ceased; thereafter he was given increasing quantities of food, and steadily gained weight and condition ( $7 \mathrm{lb}$. durirg ten days).

At midnight on February 4th he had a sudden pain in the back, at the level of the sixth dorsal spine, and a little to the left side of the middle line; this increased in severity until it was agonizing; it was accompanied by the vomiting of a large quantity of brown grumous fluid. but the vomiting gave no relief to the pain; the abdominal 